Альбина Нестерова

\title{
ДЕТИ, ОХВАЧЕННЫЕ МИГРАЦИОННЫМИ ПРОЦЕССАМИ: РАЗНООБРАЗИЕ, ВЫЗОВЫ И ДИВЕРСИФИКАЦИЯ МОДЕЛЕЙ ПОДДЕРЖКИ
}

Интенсификация миграционных процессов и их влияние на детей мигрантов создает необходимость разработки конструктивных, адаптированных с учетом возраста и социальной ситуации переселения программ развития и поддержания адаптационных ресурсов этой уязвимой группы мигрантов. Статья направлена на изучение особенностей адаптации несовершеннолетних детей мигрантов, которые не являются единой и однородной группой. В связи с этим необходим дифференцированный подход к организации сопровождения адаптационных процессов детей мигрантов, способов их поддержки. В междисциплинарном ключе рассматриваются их психосоциальные проблемы, обосновывается необходимость разработки различных для каждой группы детей способов поддержания их социального и психологического благополучия. Объектом исследования стали дети, охваченные миграционными процессами, среди которых: дети, мигрировавшие вместе с родителями (так называемое «полуторное поколение»); дети, родившиеся в семьях мигрантов в стране приема; дети-беженцы, находящиеся без сопровождения взрослых в ситуации локальных военных конфликтов; дети, оставленные/покинутые родителями-мигрантами в стране происхождения или пребывания. Так, дети, в разном возрасте покинувшие страну совместно с родителями («полуторное поколение»), часто сталкиваются с проблемой освоения языка, новой культуры, ощущением «культурной раздвоенности». Дети мигрантов, принадлежащие ко второму поколению, в большей мере демонстрируют потребность в поддержке процессов их идентификации и в развитии межкультурной компетентности. Для детей-беженцев необходима организованная психологическая помощь, которая требует профессиональной подготовки. Для детей, оставленных на родине ро-

Альбина Александровна Нестерова - д.психол.н., профессор, кафедра социальной психологии, Московский государственный областной университет, Москва, Россия. Электронная почта: anesterova77@rambler.ru 
дителями-мигрантами, нужна поддержка специалистов, понимающих психологические последствия эмоциональной депривации, разрыва привязанности и сепарации. Исследование проведено в период 2014 2017 гг. в Москве и Московской области на совокупной выборке 179 детей мигрантов. Кроме того, анализируются глубинные интервью с 18 детьми мигрантов в возрасте от 10 до 15 лет, выходцами из Узбекистана, Кыргызстана, Таджикистана, Армении, Украины, а также с их родителями и учителями.

Ключевые слова: дети мигрантов, миграционные процессы, диверсификация моделей сопровождения, адаптация

DOI: 10.17323/727-0634-2018-16-4-645-660

В настоящее время одним из ключевых вызовов является миграция и те социальные, политические, экономические и психологические процессы, которыми она сопровождается. С одной стороны, многие страны и государства заинтересованы в притоке мигрантов (Вишневский 2011). С другой стороны, миграция существенно изменяет жизнь самих мигрантов и их семей, а также влияет на экономическую и социальную ситуацию в стране приема, на уровень жизни принимающего общества (Гриценко, Шустова 2011). Несмотря на актуальность обсуждения проблем миграции, аккультурации и адаптации мигрантов, авторы часто обходят исследовательским вниманием большую социальную группу детей мигрантов, в разной степени охваченных процессами переселения. В целях данного исследования, под детьми, охваченными миграционными процессами, понимаются дети в возрасте до 18 лет, родители которых являются мигрантами (в результате чего дети проживают на территории страны, гражданами которой не являются, или остаются в стране происхождения, покинутые родителями), а равно дети, вынужденно покинувшие место своего рождения, пребывания и проживания в силу военных или иных конфликтов.

Некоторые исследования показывают, что миграция приводит детей к дистрессу, вызванному покиданием привычного социокультурного контекста, вхождением в новую культурную и языковую среду, преодолением испытаний во время переселения (Jaycox et al. 2002; Suarez-Orozco 2001). Дети мигрантов не представляют собой однородной группы, поэтому необходим дифференциальный подход к объяснению особенностей адаптации и интеграции разных групп этих детей. В некоторых странах и регионах процент несовершеннолетних мигрантов значительно выше, чем взрослых (Abramovich et al. 2011).

Настоящее исследование началось с нескольких проектов, посвященных психологической адаптации трудовых мигрантов (Нестерова, Суслова 2017; Efremova et al. 2015). C 2014 по 2016 гг. изучение было нацелено на взрослых мигрантов (486 человек, находящихся на территории Москвы и Московской 
области). В процессе интервьюирования родителей, нарративного и дискурс-анализа мы обратили внимание на «детскую проблему» миграционных процессов. Это позволило сфокусировать исследовательский интерес на особенностях адаптации детей мигрантов в продолжение работы в 2016-2017 гг. В исследовании приняло участие 179 детей, которые были опрошены с привлечением социально-психологических и психодиагностических методов. Особую ценность представляют глубинные интервью с 18 детьми мигрантов в возрасте от 10 до 15 лет, выходцев из Узбекистана, Кыргызстана, Таджикистана, Армении, Украины, а также их родителями и учителями. Именно результаты этих интервью позволили описать потребности и переживания детей мигрантов, стали основой для их классификации. В 2017 г. был инициирован опрос специалистов Центров помощи семьи и детям в Москве, целью которого стало изучение запросов мигрантов о помощи в отношении этнокультурной адаптации детей. Исследование построено на принципах социального конструкционизма, предполагающих взаимосвязь между индивидуальным пониманием мира и его социальными проявлениями (дискурс, ситуация развития, язык, культурный контекст).

\section{Поколения мигрантов: трансформация культурной идентичности и маргинальность}

Большое количество исследований вопросов миграции детей, посвящено изучению тех, кто в разном возрасте совместно с семьями покидает свой дом, переезжая в другие регионы и страны (см.: Бредникова, Сабирова 2015; Макаров 2010; Capps et al. 2005; Shields 2004). Вопросы адаптации, особенностей аккультурации детей мигрантов остаются предметом исследований различных наук. Для этой группы разработано множество программ социально-психологического сопровождения, апробированы механизмы оказания социальной помощи, как посредством работы с самими детьми, так и с основными агентами социализации (родителями, родственниками, педагогами). Однако назрела необходимость разделить детей мигрантов на подгруппы, исходя из психологических, социальных, образовательных запросов и потребностей, что позволит определить направления успешной социальной политики в данной области.

Самым простым критерием такой дифференциации является возраст детей. Тех, кто рождается у мигрировавших в новую страну пребывания родителей, относят ко второму поколению мигрантов, а тех, кто эмигрируют в другую страну вместе с родителями в возрасте до 12 лет, называют «полуторное поколение» мигрантов (Рочева 2011; Benesch 2008; Danico 2004). Социолог Рубен Румбо (Rumbaut 2007) в зависимости от факторов социализации ребенка предлагает следующее деление: 1,75-поколение (дети, переселившиеся до 6 лет), 1,5-поколение (дети, переселившиеся в возрасте от 6 до 12 лет) и 1,25-поколение (дети, переселившиеся в под- 
ростковом возрасте). Учет возраста переселения очень важен, так как в рамках исследований подтверждается, что наиболее уязвимыми являются группы несовершеннолетних 1,25- и 1,75-поколений (Garcia-Coll, Magnusen 1997). Для детей дошкольного возраста (1,75-поколение) миграция является тяжелым испытанием, так как до поступления в школу они только начинают встраиваться в систему социокультурных традиций и норм одной страны, и, как следствие, при переезде в новую культурную среду могут испытывать трудности с адаптацией. Для подростков (1,25-поколение) период аккультурации осложняется процессами, связанными со становлением собственной идентичности.

Несмотря на разные классификации детей мигрантов по критерию возраста, большинство ученых сходятся во мнении, что группа «промежуточных поколений» детей мигрантов по своему социальному статусу, характеру трансформационных процессов, формированию разных видов идентичности (социальной, этнической, культурной, гражданской, религиозной) отличается переходным, маргинальным, «подвешенным» состоянием между двумя культурами: культурой происхождения и принимающей культурой (Рочева 2011; Danico 2004). Представителей полуторного поколения детей мигрантов характеризует неопределенная идентичность и промежуточное положение. Даже взрослые мигранты, состоявшиеся как личности, зачастую подвержены маргинализации в ситуации переселения и аккультурации. Представителей полуторного поколения, привезенных по воле родители в другую страну, исследователи часто характеризуют как «маргиналов второй степени». Эта группа по факту имеет принадлежность к двум культурам, и в то же время в полной мере не принадлежит ни к одной (Adelman, Taylor 2015; Park 1999). В этой группе наблюдается некоторый разрыв, культурная дистанция и с представителями своей культуры, и с представителями новой принимающей среды.

\section{Дети «третьей культуры»}

Исследование, проведенное в школах нескольких городов России, показало, что мигранты 1,5-поколения занимают ощутимую нишу в образовательных организациях России и представлены в большом количестве выходцами из Средней Азии (Узбекистан, Кыргызстан, Таджикистан). Среди представителей второго поколения детей мигрантов преобладают дети из Армении и Украины (Александров и др. 2011). Наши исследования, проведенные в школах Москвы и Московской области в 2016 г., демонстрируют, что подавляющее число несовершеннолетних мигрантов - это дети полуторного и второго поколения. Это одна из самых многочисленных групп детей мигрантов, поэтому для них необходимо разработать комплекс мер и механизмы социальной поддержки с целью нивелирования социальных и психологических проблем, с которыми они сталкиваются. 
В интервью с детьми и их родителями мы зафиксировали проблемы языковой адаптации, множественной идентичности, маргинальности, «культурной раздвоенности»:

я теперь даже не знаю, кто больше я. Вроде я и киргиз, мои родители киргизы, но мне теперь больше нравится здесь, в России. Мне кажется, что я уже стал русским (мальчик, 12 лет, Кыргызстан).

Некоторые дети испытывают трудности в самоидентификации, переживают, что часто чувствуют изоляцию в группах сверстников: «Все равно, мне кажется, что одноклассники ко мне относятся не так как к другим детям; девочки меня не зовут гулять и в свои игры не приглашают» (девочка, 10 лет, Кыргызстан). Также дети отмечали, что их культура происхождения не всегда позволяет им «вписаться» в подростковую культуру принимающей стороны. При этом дети из Армении и Украины гораздо лучше вписываются в образовательную среду школы, что говорит о некоторой культурно обусловленной специфике данного процесса.

В организации помощи этой группе детей важно учитывать необходимость психологической поддержки, оказываемой образовательной организацией (школьный психолог, педагоги дополнительного образования), а также важна помощь в преодолении языкового барьера, в чем могут помочь педагоги школы, специалисты районных Центров помощи семьи и детям.

У детей мигрантов «второго поколения» одна из основных задач развития - освоить одновременно две культуры, два языка. При этом процесс может проходить при невозможности полной идентификации ни с одной из культур. Дети этой группы получают ценностные ориентиры, узнают нормы и обычаи, которые передают им родители. Однако они также осваивают те ценности, которые продвигаются культурой принимающего сообщества через контексты локальных институтов социализации. Сравнение и противопоставление этих двух культур в картине мира ребенка можно описать как «конфликт культур». При отсутствии должной поддержки и внимания к проблемам детей с «культурной раздвоенностью», они могут попасть в сложную ситуацию, вынужденные делать эмоционально болезненный выбор между культурой происхождения, транслируемой родителями, и основными социокультурными нормами, которые передаются в детских сообществах принимающей культуры. Например, девочка из Узбекистана 14 лет очень переживала, что ее мама не отпускает на ночлег к подружке, поскольку это не принято в их культуре, в то время как в их классе все девочки так делают, и родители разрешают.

Необходимо отметить важность социальной поддержки детей мигрантов, ориентированных на приобретение бикультурной (межкультурной) компетентности, т.е. способности легко, комфортно и адекватно взаимодействовать с представителями разных культур. Наши исследования показывают, что дети, обладающие высоким уровнем жизнеспособности, 
обладают также и высоким уровнем межкультурной компетентности. Хорошо приспосабливаются к новой культуре, легко осваивают ее правила и нормы, способны найти себе друзей в новой культуре. Согласно исследованию Синтии Гарсия-Колл и Катерины Магнусон, культурный дуализм имеет важные последствия для второго и третьего поколения семей мигрантов. Бикультурная компетентность включает в себя знание культурных убеждений и ценностей, позитивное отношение к группам социокультурного большинства и меньшинства, чувство самоэффективности в обеих культурах, коммуникативные способности, владение репертуаром приемлемых ролей, наличие развитой социальной поддержки (Garcia-Coll, Magnuson 1997: 109).

Принимающее сообщество в лице помогающих служб и сервисов ориентировано на адаптацию мигрантов первого поколения - взрослых мигрантов. Между тем «полуторное» поколение, которое прибыло в другую страну по воле своих родителей и старших членов семьи (т.е. самостоятельно не принимали решения о миграции и никак не участвовали в этом решении), а также второе поколение детей, рожденных в другой стране, часто теряют ориентиры и могут переживать культурный шок. Наши исследования подтвердили, что в территориальные центры помощи семьям и детям редко обращаются мигранты по вопросам, связанным с проблемами детей. В эти центры семьи мигрантов приходят по поводу проблем с жильем, вопросов правового характера или собственных языковых проблем. Взрослые мигранты в отношении детей идут лишь за помощью по устройству ребенка в образовательную организацию либо для правового сопровождения этого вопроса.

Опыт детей описанной группы не является однородным, он связан с множеством факторов и условий, которые влияют на их интеграцию и идентификацию. Некоторые исследования подтверждают, что иногда дети становятся проводниками новой культуры для своих родителей-мигрантов, проходя более эффективно процесс языковой адаптации, лучше воспринимая и исполняя социальные роли, заданные новой культурой (Jones, Trickett 2005). Так, исследования эмигрантов из России в США доказали, что подростки-иммигранты в большей степени отождествляют себя с русской культурой, чем родители (Birman, Trickett 2001). При этом важно не обойти вниманием те группы детей, для которых процессы адаптации и аккультурации в новой среде проходят более болезненно.

\section{Дети, переживающие травматический стресс и боль утраты}

Дети-беженцы, дети вынужденных переселенцев, а также дети, попавшие в миграционные потоки под давлением внешних обстоятельств и катаклизмов - это особая группа детей мигрантов. Дискурс о мигрантах наполнен различными понятиями, которые до конца в правовом поле 
не определены. Это обуславливает путаницу в употреблении терминов. В российских реалиях наблюдаются сложности в операционализации понятий «беженец», «лицо в поисках убежища», «вынужденный переселенец» (Гулина 2016:336). Эти сложности в определении статуса «беженца» касаются как взрослых мигрантов, так и их детей, не достигших совершеннолетия. Согласно законодательству РФ, беженец - это лицо, которое не является гражданином РФ и которое в силу обоснованных опасений стать жертвой преследований по разным признакам (расы, вероисповедания, принадлежности к определённой социальной группе) находится вне страны своей гражданской принадлежности и не может пользоваться защитой этой страны (Федеральный закон 1997).

Дети-беженцы представляют собой весомую по количеству группу мигрантов, которая заслуживает особого внимания по причине множества социальных, правовых и психологических проблем, обусловленных вынужденной ситуацией переселения. Так, например, Барбара Лоу и Мэри Экес пишут, что «[и]ммигрант покидает свою родину, чтобы найти траву зеленее. Беженец покидает свою родину, потому что у него трава горит под ногами» (Law, Eckes 2000: 86). По оценкам ЮНИСЕФ в 2017 г. около 68,5 млн человек по всему миру стали беженцами из-за военных конфликтов, актов насилия и преследования. При этом $80 \%$ жертв современных войн и конфликтов - женщины и дети. Они вынуждены бежать из своих стран в поисках убежища и безопасности (UNHCR 2017). Неудивительно, что $53 \%$ беженцев во всем мире - это несовершеннолетние. Ситуация усложняется, когда дети-беженцы находятся в одиночестве, без родителей и сопровождающих взрослых. Дети-беженцы без сопровождения взрослых - это одна из самых уязвимых групп мигрантов. Среди них есть и те, кто имеет опыт принуждения со стороны взрослых для участия в открытых вооруженных конфликтах. Также эти дети могут сталкиваться с такими травматичными ситуациями, оказывающими воздействие на их дальнейшее развитие, как сексуальное/физическое насилие, пытки, иные травмы. Они могут иметь опыт вовлечения в преступную деятельность, злоупотребления психоактивными веществами. Могут переживать депрессию, горе и утрату (Lustig et al. 2004).

Ренос Пападопулос предлагает авторскую концептуализацию хронологии адаптационного процесса для каждого беженца, которая включает следующие стадии: антиципация; переживание травматичных событий; выживание; приспособление (Papadopoulos 2001). В то же время хронология маргинализационного процесса состоит как из отторжения в стране происхождения, так и из нового опыта неприятия, интолерантности, социальной и культурной изоляции, дискриминации, с которой беженцы часто сталкиваются в принимающей стране. Интервью с ребенком тринадцати лет вынужденно покинувшим территорию Украины в результате военных действий это подтверждает: 
Мне здесь очень плохо. У меня там остались друзья, бабушка, собака. Тут совсем другие люди, какие-то недружные, злые. Я хочу вернуться домой, но отец говорит, что мы здесь останемся навсегда. Я все равно уеду обратно, как только смогу.

Опыт вынужденного «вырывания корней» осложняет развитие ребенка разрушительными процессами, такими как ощущение бессилия, неопределённости и беспомощности; утрата целостности семьи; невозможность опереться на ресурсы оставленных социальных сетей поддержки (родственников, друзей); переживание горя и одиночества. Службы сопровождения этой группы детей должны иметь представления о правовых сложностях в определении статуса ребенка, о перспективах его проживания в стране пребывания и возможности реабилитации после пережитой психологической травмы. Социальная поддержка детей и подростков требует от специалиста высокой правовой культуры, понимания специфики социальной работы с беженцами в стране пребывания, а также глубоких знаний в области психотерапии детской травмы, хронических и искаженных форм горя, нивелирования психологических последствий насилия и жестокого обращения.

\section{Дети, оставленные мигрантами в стране происхождения}

Еще одна группа детей мигрантов, проблемы которой в меньшей степени затрагиваются в научной литературе и обсуждаются на дискуссионных площадках - это группа детей, оставленных родителями-мигрантами в стране происхождения (Left Behind children). Родители-мигранты, принимая решение о постоянной или маятниковой миграции, сталкиваются с необходимостью оставить своих детей на родине. Часто решения одного или обоих родителей покинуть родину и ребенка основывается на альтруистическом желании материально обеспечить свою семью и обеспечить детям «лучшую жизнь». В ряде стран на постсоветском пространстве, таких как Молдова, Таджикистан, растет число детей, оставленных родителями дома. Это, несомненно, требует изучения и разработки стратегий психосоциальной помощи данной группе несовершеннолетних. Несмотря на то, что нет достоверных данных о количестве детей, оставленных родителями на время миграции, данные национальных статистических служб ряда стран, представленные ниже, свидетельствуют о росте данного явления.

Например, в сельских районах Китая число детей, оставленных родителями и уехавшими в миграцию, составляет 61,0 млн человек. Это 37,7\% от общего числа детей в сельской местности и $21,9 \%$ от общего числа детей в КНP (Tian et al. 2017). Статистика Филиппин констатирует наличие 9 млн детей, оставшихся дома, что составляет $27 \%$ от общего числа несовершеннолетних в стране (Parreñas 2005: 317). В Индонезии регистрируют 700 тыс. таких детей, в Таиланде - полмиллиона (Bryant 2005). В Молдове около 
177000 детей в возрасте до 18 лет, оставшихся без родителей, уехавших на заработки за границу (Salah 2008). Очень сложная ситуация в Таджикистане, где масштабное исследование детей, оставленных родителями из-за миграции в другие страны, вскрыло большое количество социальных и психологических проблем (UNICEF 2011). Несмотря на отмечаемое исследователями позитивное воздействие миграции на экономику страны и домохозяйств, заключающееся в получении дополнительных доходов для оплаты услуг здравоохранения и образования, $80 \%$ покинутых семей отмечают негативное влияние миграции на их семьи. Оставление детей уезжающими на заработки родителями ведет к негативной динамике в развитии и становлении личности ребенка, отражается на снижении уровня образования и академической успешности детей; ухудшении качества питания, уровня здоровья из-за интенсивности домашнего труда и высокого уровня заболеваемости (туберкулез, ВИЧ), наличию серьезных поведенческих проблем со стороны несовершеннолетних, в том числе правонарушений.

Наше исследование детей, чьи родители уехали на заработки в другую страну, подтвердило, что возможность поехать к родителям, посмотреть другую страну, подарки и деньги от родителей рассматриваются детьми как позитивные факторы. При этом дети, оставленные родителями (особенно девочки), отмечают, что их смущает, когда на школьные мероприятия приходят не родители, а другие родственники; сетуют на то, что иногда не с кем поделиться своими огорчениями. Из интервью девочки 13-ти лет, мама и отчим которой эмигрировали:

Я живу с бабушкой, но она очень старенькая и уже не может понять, что мне интересно и хочется. Родители [мама и отчим] отдают все деньги ей, а она их тратит по своему усмотрению. А мне хочется одеваться, как другие девочки. Я должна присматривать и за ней, и за своим младшим братом. А когда мне гулять? И вообще бывает так грустно, а мамы рядом нет... по телефону это не обсудишь... Почему она не забрала меня с собой?

По данным проведенных нами исследований, можно констатировать, что оставленные родителями-мигрантами дети получают меньше эмоциональной поддержки, чем их сверстники. Их семьи способны дать им гораздо меньшее количество ресурсов, необходимых для достойного образования (не столько материальных, а, прежде всего, выражающихся в деятельном участии и вовлеченности родителя в процесс обучения и воспитания ребенка). Кроме того, эти дети лишены семейной атмосферы, родительской любви, надежной привязанности. Они обделены общением с родителями, хотя у них могут быть более благоприятные финансовые условия, чем у их сверстников. Этим детям часто приходится заботиться о прародителях, других родственниках, они вынуждены решать разнообразные ежедневные проблемы в одиночку, преодолевая давление несоответствующей возрасту наложенной на них ответственности. 
Грасиэлой Кастекс (Castex 1997) отмечено, что после воссоединения семей с детьми, оставленными родителями, могут возникнуть проблемы между родителями и «покинутыми» детьми, находящимися в подростковом возрасте, так как дети пытаются утвердить свою власть и не готовы подчиняться родителям. Кроме того, маленькие дети могут не понимать причин, по которым они были оставлены родителями, следовательно, склоны испытывать смешанные чувства к перспективе воссоединения. Часто первоначальное чувство счастья, связанное с долгожданным воссоединением семьи, сменяется печалью и ощущением утраты опекунов, друзей и объектов привязанности.

Среди факторов риска, препятствующих позитивной социализации оставленных детей, можно отметить снижение самооценки, академической успеваемости, формирование недоброжелательности к окружающим, презрение к родителям, обидчивость и ранимость, дурные привычки и аддиктивные формы поведения. Основными «мишенями» для психосоциального сопровождения этой группы детей должна стать работа, направленная на выстраивание привязанностей ребенка, поддержания в нем чувства собственной значимости, нужности и самоэффективности. Также необходима поддержка детей и их опекунов в обеспечении более интенсивного общения с родителями, которые находятся за границей. Важной формой психосоциальной работы является организация условий для развития жизнеспособности ребенка, оставленного родителями, его сопротивляемости стрессу разлуки с родителями; создание безопасной поддерживающей социальной сети из значимых и авторитетных для ребенка взрослых.

\section{Заключение}

Дети мигрантов - это разнородная по своим демографическим показателям, социальному и правовому статусу группа детей, охваченных миграционными процессами. Их различают причины переселения, определяемые детерминантами миграции взрослых. Представляется, что общее определение - «дети в процессе миграции» (children on the move) в научной литературе приводит к необоснованному объединению в единую матрицу нужд и потребностей разных социальных групп несовершеннолетних. Между тем, как показывает наше исследование, вышеперечисленные в данной статье группы детей мигрантов отличаются по разным показателям, а потому нуждаются в дифференцированных видах помощи.

Так, дети, в разном возрасте покинувшие страну совместно с родителями («полуторное поколение»), часто сталкиваются с проблемой освоения языка, новой культуры, ощущением «культурной раздвоенности». Чем в более старшем возрасте ребенок переезжает, тем труднее ему учить язык. Наиболее востребованная помощь этой группе детей будет заключаться, прежде всего, в сопровождении ребенка и его семьи психологической службой школы, 
в помощи педагогов школ в преодолении языкового барьера. Также необходимо подключать специалистов различных территориальных Центров помощи семьи и детям к организации консультаций для родителей, в том числе и касающихся воспитания и позитивной адаптации ребенка. Хорошо, если в помощь и сопровождение адаптации ребенка «полуторного поколения» будут включены педагоги дополнительного образования, работающие в местных клубах, библиотеках, кружках и секциях.

Дети мигрантов, принадлежащие ко второму поколению, в большей мере демонстрируют потребность в поддержке процессов их идентификации и в развитии межкультурной компетентности. Образовательные организации в целях поддержки этих детей могут проводить тренинги межкультурной компетентности, толерантности, мероприятия, посвященные расширению знаний о различных культурах. В данном случае упор необходимо сделать на культурно-просветительской работе, в которую должны быть включены дети и родители-мигранты, равно как дети и родители, представляющие принимающее общество. В некоторых школах РФ хорошо зарекомендовали себя разработанные психологами и распространяемые в школах памятки для родителей-мигрантов (часто на их родном языке), в том числе сведения об организациях, где семьи мигрантов могут получить различную помощь. Такой опыт имеется в Санкт-Петербурге.

Для детей-беженцев требуется организованная психологическая помощь, которая требует специальной профессиональной подготовки. Такую помощь должны оказывать специалисты-психологи, хорошо знакомые со спецификой переживания горя и травмы. Обычно территориальные психологические службы имеют в своем штате специалистов, которые профессионально могут выполнять эту работу.

Дети, оставшиеся дома, в результате миграции родителей, также не должны быть обделены вниманием психологической службы школы или других организаций, оказывающих социальную и психологическую помощь населению. Этой группе детей требуется поддержка специалистов, понимающих психологические последствия эмоциональной депривации, разрыва значимых для ребенка близких отношений. Для таких детей может быть рекомендована помощь школьного психолога, социального педагога образовательной организации, которую ребенок посещает.

На сегодняшний день в Российской Федерации назрела острая необходимость в создании отдельной структуры или организации, которая бы представляла интересы разных групп детей мигрантов с целью оказания помощи им и их семьям в разрешении правовых, социальных и психологических проблем. Также диверсификация моделей организации сопровождения для разных групп детей, охваченных миграционными процессами, возможна при участии различных институтов и служб международного и национального уровней, занимающихся проблемами мигрантов. Важную роль в организации диверсифицированной поддержки детям мигрантов 
и их семьям играет профессиональное экспертное сообщество, призванное в междисциплинарном ключе и атмосфере сотрудничества разработать технологии для сопровождения адаптационных процессов детей мигрантов, по разным причинам участвующих в миграционных процессах.

\section{Выражение признательности}

Статья подготовлена при финансовой поддержке РФФИ в рамках научного проекта № 18-013-00606 (код_а).

\section{Список источников}

Александров Д., Баранова В., Иванюшина В. (2011) Дети из семей мигрантов в школах Санкт-Петербурга: предварительные данные. СПб.: Издательство Политехнического университета.

Бредникова О., Сабирова Г. (2015) Дети в мигрантских семьях: родительские стратегии в транснациональных контекстах. Антропологический форум, (26): 127-152.

Вишневский А. (2011) Миграционная стратегия России и политика толерантности. Наииональный психологический журнал, 2 (6): 90-97.

Гриценко В., Шустова Н. (2011) Социально-психологическая адаптация детей из семей мигрантов. М.: Форум.

Гулина О. (2016) Семантика миграционных терминов. Журнал исследований социальной политики, 14 (3):331-346.

Макаров А. (2010) Особенности этнокультурной адаптации детей мигрантов в московских школах. Социологические исследования, (8):94-101.

Нестерова А., Суслова Т. (2017) Ментальные репрезентации как фактор протекания миграционного процесса. Социологические исследования, (9):99-107.

Рочева А. (2011) «Полуторное» поколение мигрантов: множественная маргинальность (обзор литературы). Доступно по ссылке: http://www.isras.ru/publ.html?id=2355 (дата обращения: 1 декабря 2017).

Федеральный закон (1997) О беженцах № 95-ФЗ от 28 июня 1997 г.

Abramovich V., Cernadas P., Morlachetti A. (2011) The Rights of Children, Youth and Women: Conceptual Basis and Principles for Effective Policies with a Human Rights and Gender Based Approach. New York: UNICEF.

Adelman H., Taylor L. (2015) Immigrant children and youth in the USA: Facilitating Equity of Opportunity at School. Education Sciences, (5): 323-344.

Benesch S. (2008) 'Generation 1.5' and its Discourses of Partiality: A Critical Analysis. Journal of Language, Identity, and Education, 7 (3/4):294-311.

Birman D., Trickett E. (2001) Cultural Transitions in First-generation Immigrants - Acculturation of Soviet Jewish Refugee Adolescents and Parents. Journal of CrossCultural Psychology, 32 (4): 456-477.

Bryant J. (2005) Children of International Migrants in Indonesia, Thailand, and the Philippines: A Review of Evidence and Policies. Florence: Innocenti Working Paper.

Capps R., Fix M., Ost J., Reardon-Anderson J., Passel J. (2005) The Health and Well-being of Young Children of Immigrants. Washington, DC: The Urban Institute. 
Castex G. (1997) Immigrant Children in the United States. N. Phillips, S. Straussner (eds.) Urban Environment: Linking Social Policy and Clinical Practice. Sprinfield, IL: Charles C. Thomas Publisher: 43-60.

Danico Y. (2004) The 1.5 Generation: Becoming Korean American in Hawaii. Honolulu: University of Hawaii Press.

Efremova G., Nesterova A., Suslova T., Pavlova O. (2015) Constructivist Approach to the Problem of Social Psychological Adaptation of Migrants. Asian Social Science, 11 (1): 112-118.

Garcia-Coll C., Magnusen K. (1997) The Psychological Experience of Immigration: A Developmental Perspective. A. Booth, A. Crouter, N. Landale (eds.) Immigration and the Family. Mahwah: Lawrence Erlbaum Associates:91-131.

Jaycox L., Stein B., Kataoka S., Wong M., Fink A., Escudero P. (2002) Violence Exposure, Posttraumatic Stress Disorder, and Depressive Symptoms among Recent Immigrant Children. Journal of the American Academy of Child and Adolescent Psychiatry, (41): 1104-1111.

Jones C., Trickett E. (2005) Immigrant Adolescents Behaving as Culture Brokers: A Study of Families from the Former Soviet Union. The Journal of Social Psychology, 145 (4): 405-427.

Law B., Eckes M. (2000) The More-Than-Just-Surviving Handbook: ESL for Every Classroom Teacher. Winnipeg: Portage \& Main Press.

Lustig S., Kia-Keating M., Knight W., Geltman P., Ellis H., Kinzie J., Keane T., Saxe G. (2004) Review of Child and Adolescent Refugee Mental Health. Journal of the American Academy of Child \& Adolescent Psychiatry, 43(1):24-36.

Papadopoulos R. (2001) Refugee Families: Issues of Systemic Supervision. Journal of Family Therapy, 23 (4): 405-422.

Park K. (1999) 'I Really do Feel I'm 1.5!': The Construction of Self and Community by Young Korean Americans. L. Baker (ed.) Life in America: Identity and Everyday Experience. Oxford: Blackwell: 123-136.

Parreñas R. (2005) Children of Global Migration: Transnational Families and Gendered Woes. Stanford, CA: Stanford University Press.

Rumbaut R. (2007) Ages, Life Stages, and Generational Cohorts: Decomposing the Immigrant First and Second Generations in the United States. A. Portes, J. DeWind (eds.) Rethinking Migration: New Theoretical and Empirical Perspectives. New York: Berghahn Books:342-390.

Salah M. (2008) The Impacts of Migration on Children in Moldova. New York: UNICEF.

Shields M. (2004) Children of Immigrant Families: Analysis and Recommendations. The Future of Children, 14 (2): 4-15.

Suarez-Orozco C., Suarez-Orozco M. (2001) Children of Immigration. Cambridge, MA: Harvard University Press.

Tian X., Ding C., Shen Ch., Wang H. (2017) Does Parental Migration Have Negative Impact on the Growth of Left-Behind Children?-New Evidence from Longitudinal Data in Rural China. International Journal of Environmental Research and Public Health, 14 (11): 1308.

UNHCR (2017) Figures at a Glance: Statistical Yearbooks. Available at: http://www.unher. org/figures-at-a-glance.html (accessed 22 December 2017).

UNICEF (2011) Impact of Labour Migration on Children Left Behind in Tajikistan. Available at: https://www.unicef.org/tajikistan/Web_Migration_Report_Eng_light.pdf (accessed 22 December 2017). 


\title{
CHILDREN IN MIGRATION PROCESSES: DIVERSITY, CHALLENGES, AND DIVERSIFICATION OF MODELS OF ADAPTATION
}

\begin{abstract}
This article explores the features of child migrant adaptation, a group that is not a single and homogeneous group. In this regard, a differentiated approach to organizing support for adaptation is needed. This study focuses on children involved in migration processes, including: those who migrated with their parents (the so-called '1.5-generation'); children who were born in migrant families in another country; refugee children in danger such as those without the accompaniment of adults or in situations of local military conflicts); 'Left Behind Children' - those whose parents have migrated out of the country leaving them behind. Thus, children of different ages who left the country together with their parents (the '1.5-generation') often face the challenge of language acquisition, a new culture, a sense of 'cultural duality'. The children of migrants belonging to the second generation, to a greater extent demonstrate the need for support of the processes of their identification and development of intercultural competence. Refugee children need more complex organized psychological assistance, which often requires special training. For those children left behind by parents-emigrants, the support of specialists who understand the psychological consequences of emotional deprivation is required to manage attachment disorder and the effects of separation. The studies were conducted in the period 2014-2017 in Moscow and the Moscow region on a total sample of 179 migrant children. The article also presents the results of in-depth interviews conducted with eighteen children of migrants aged ten to fifteen years, immigrants from Uzbekistan, Kyrgyzstan, Tajikistan, Armenia, Ukraine, as well as their parents and teachers.
\end{abstract}

Key words: children of migrants, migration processes, diversification of models of support, adaptation

DOI: 10.17323/727-0634-2018-16-4-645-660

\section{References}

Abramovich V., Cernadas P., Morlachetti A. (2011) The Rights of Children, Youth and Women: Conceptual Basis and Principles for Effective Policies with a Human Rights and Gender Based Approach. New York: UNICEF.

Adelman H., Taylor L. (2015) Immigrant Children and Youth in the USA: Facilitating Equity of Opportunity at School. Education Sciences, (5): 323-344.

Albina Nesterova - Doctor of Psychology, Professor at the Department of Social Psychology, Moscow Region State University, Moscow, Russian Federation. Email: anesterova77@rambler.ru 
Alexandrov D., Baranova V., Ivaniushina V. (2011) Deti iz semey migrantov v shkolakh Sankt-Peterburga: predvaritelnye dannye [Children from Migrant Families in Schools of Saint Petersburg: Preliminary Findings]. St. Petersburg: Polytechnic University Press.

Benesch S. (2008) 'Generation 1.5' and its Discourses of Partiality: A Critical Analysis. Journal of Language, Identity, and Education, 7 (3/4):294-311.

Birman D., Trickett E. (2001) Cultural Transitions in First-generation Immigrants - Acculturation of Soviet Jewish Refugee Adolescents and Parents. Journal of CrossCultural Psychology, 32 (4): 456-477.

Bryant J. (2005) Children of International Migrants in Indonesia, Thailand, and the Philippines: A Review of Evidence and Policies. Florence: Innocenti Working Paper.

Capps R., Fix M., Ost J., Reardon-Anderson J., Passel J. (2005) The Health and Well-being of Young Children of Immigrants. Washington, DC: The Urban Institute.

Castex G. (1997) Immigrant Children in the United States. N. Phillips, S. Straussner (eds.) Urban Environment: Linking Social Policy and Clinical Practice. Sprinfield, IL: Charles C. Thomas Publisher: 43-60.

Danico Y. (2004) The 1.5 Generation: Becoming Korean American in Hawaii. Honolulu: University of Hawaii Press.

Efremova G., Nesterova A., Suslova T., Pavlova O. (2015) Constructivist Approach to the Problem of Social Psychological Adaptation of Migrants. Asian Social Science, 11 (1): 112-118.

Federal Law (1997) O bezhentsah [On Refugees] N95-FZ from 28.06.1997.

Garcia-Coll C., Magnusen K. (1997) The Psychological Experience of Immigration: A Developmental Perspective. A. Booth, A. Crouter, N. Landale (eds.) Immigration and the Family. Mahwah: Lawrence Erlbaum Associates:91-131.

Gricenko V., Shustova N. (2011) Social'no-psihologicheskaja adaptacija detej iz semej migrantov [Socio-psychological Adaptation of Children from Migrant Families]. Moscow: Forum.

Gulina O. (2016) Semantika migracionnyh terminov [Exploring the Semantics of Migration Terminology]. The Journal of Social Policy Studies, 14 (3):331-346.

Jaycox L., Stein B., Kataoka S., Wong M., Fink A., Escudero P. (2002) Violence Exposure, Posttraumatic Stress Disorder, and Depressive Symptoms among Recent Immigrant Children. Journal of the American Academy of Child and Adolescent Psychiatry, (41): 1104-1111.

Jones C., Trickett E. (2005) Immigrant Adolescents Behaving as Culture Brokers: A Study of Families from the Former Soviet Union. The Journal of Social Psychology, 145 (4): 405-427.

Law B., Eckes M. (2000) The More-Than-Just-Surviving Handbook: ESL for Every Classroom Teacher. Winnipeg: Portage \& Main Press.

Lustig S., Kia-Keating M., Knight W., Geltman P., Ellis H., Kinzie J., Keane T., Saxe G. (2004) Review of Child and Adolescent Refugee Mental Health. Journal of the American Academy of Child \& Adolescent Psychiatry, 43 (1):24-36.

Makarov A. (2010) Osobennosti jetnokul'turnoj adaptacii detej migrantov v moskovskih shkolah [Features of Ethno-Cultural Adaptation of Migrants' Children in Moscow Schools]. Sotsiologicheskie issledovaniya [Sociological research], (8): 94-101. 
Nesterova A., Suslova T. (2017) Mental'nye reprezentacii kak faktor protekanija migracionnogo processa [Mental Representations as a Factor of the Migration Process]. Sotsiologicheskie issledovaniya [Sociological Research], (9): 99-107.

Papadopoulos R. (2001) Refugee Families: Issues of Systemic Supervision. Journal of Family Therapy, 23 (4): 405-422.

Park K. (1999) 'I really do feel I'm 1.5!': The Construction of Self and Community by Young Korean Americans. L. Baker (ed.) Life in America: Identity and Everyday Experience. Oxford: Blackwell: 123-136.

Parreñas R. (2005) Children of Global Migration: Transnational Families and Gendered Woes. Stanford, CA: Stanford University Press.

Rocheva A. (2011) 'Polutornoe' pokolenie migrantov: mnozhestvennaja marginal'nost' (obzor literatury) [The 'One and a Half' Generation of Migrants: Multiple Marginality. (a Literature Review)]. Available at: http://www.isras.ru/publ.html?id=2355 (accessed: 01 December 2017).

Rumbaut R. (2007) Ages, Life Stages, and Generational Cohorts: Decomposing the Immigrant First and Second Generations in the United States. A. Portes, J. DeWind (eds.) Rethinking Migration: New Theoretical and Empirical Perspectives. New York: Berghahn Books:342-390.

Salah M. (2008) The Impacts of Migration on Children in Moldova. New York: UNICEF.

Shields M. (2004) Children of Immigrant Families: Analysis and Recommendations. The Future of Children, 14 (2): 4-15.

Suarez-Orozco C., Suarez-Orozco M. (2001) Children of Immigration. Cambridge, MA: Harvard University Press.

Tian X., Ding C., Shen Ch., Wang H. (2017) Does Parental Migration Have Negative Impact on the Growth of Left-Behind Children?-New Evidence from Longitudinal Data in Rural China. International Journal of Environmental Research and Public Health, 14 (11): 1308.

UNHCR (2017) Figures at a Glance: Statistical Yearbooks. Available at: http://www.unhcr.org/figures-at-a-glance.html (accessed 22 December 2017).

UNICEF (2011) Impact of Labour Migration on Children Left Behind in Tajikistan. Available at: https://www.unicef.org/tajikistan/Web_Migration_Report_Eng_light.pdf (accessed 22 December 2017).

Vishnevskij A. (2011) Migracionnaja strategija Rossii i politika tolerantnosti [The Migration Strategy of Russia and Tolerance Policy]. National Psychological Journal, 2 (6): 90-97. 